\title{
Management of psychosis in patients with Alzheimer's disease: focus on aripiprazole
}

\author{
Subramanian \\ Madhusoodanan' \\ Payal Shah ${ }^{2}$ \\ 'St John's Episcopal Hospital Far \\ Rockaway, NY II69I, SUNY, Brooklyn \\ NY, USA. ${ }^{2}$ SUNY Health Science \\ Center, Brooklyn, NY
}

\begin{abstract}
Psychosis of Alzheimer's disease (AD) is characterized by delusions or hallucinations and may be associated with agitation, negative symptoms or depression. There are no psychotropic medications that are approved by the US FDA for the treatment of psychosis of AD. However, atypical antipsychotics have been widely used and recommended by geriatric experts in the management of psychosis of $\mathrm{AD}$ in view of the modest efficacy and relative safety until FDA warnings were issued in 2005 and meta-analytic studies showed no significant difference to placebo. The FDA warnings on the cardiac, metabolic, cerebrovascular, and mortality risks have caused serious concerns for the use of atypical antipsychotic agents in elderly patients with dementia. Only a few studies have evaluated prospectively the effects of aripiprazole in psychosis associated with AD. These studies show improvement in the symptoms of psychosis associated with AD with aripiprazole. The safety and tolerability profile of aripiprazole suggests a low potential for negative impact on dementia and overall patient health. Further studies comparing the efficacy and tolerability of aripiprazole vs other atypical antipsychotics in dementia are needed.
\end{abstract}

Keywords: treatment, Alzheimer's dementia, psychosis, aripiprazole

\section{Introduction}

Alzheimer's disease (AD) affects 5\%-15\% of the population over 65 years, and about $20 \%$ of individuals over 80 years. AD is characterized by a gradual onset of multiple cognitive deficits and is associated with continuing cognitive decline. There is a high prevalence of psychotic symptoms (Paulsen et al 2000) and behavioral disturbances in AD (Devanand et al 1992; Eustace et al 2002). A review of studies that assessed the prevalence of psychosis associated with AD showed a median prevalence rate of 41.1\% (range, 12.2\%-74.1\%) (Ropacki and Jeste 2005); however, the patients followed up in the outpatient clinics showed lower rates (Bassiony et al 2000). Psychotic symptoms have been linked to increased cognitive and functional decline (Chui et al 1994; Lopez et al 1999) leading to caregiver distress (Everitt et al 1991; Hopkins and Libon 2005) and an increased likelihood of institutionalization (Lopez et al 1999) in patients with AD. Jeste and Finkel (2000) have defined the diagnostic criteria for psychosis of AD (Table 1).

Among the psychotropic medications, antipsychotics are the most studied treatment for psychosis, aggression, and agitation in elderly patients with dementia (Doody et al 2001; Kindermann et al 2002). These studies have shown the efficacy of atypical antipsychotics in treating some of the behavioral symptoms that are associated with AD (Katz et al 1999; Street et al 2000; Tariot et al 2002; Brodaty et al 2003; De Deyn et al 1999, 2004; Zhong et al 2004). Even though there is no psychotropic medication that is approved by the US Food and Drug Administration (FDA) for the treatment of psychosis of $\mathrm{AD}$, a number of expert consensus statements recommend the use of atypical antipsychotic agents as a first-line pharmacologic approach to 
Table I Diagnostic Criteria for psychosis of Alzheimer's disease (PAD) (after Jeste and Finkel 2000)

\author{
Characteristic symptoms \\ Presence of $\geq 1$ of the following: \\ Visual or auditory hallucinations \\ Delusions \\ Primary diagnosis \\ All criteria for dementia of Alzheimer's type are met. \\ Chronology of onset of psychosis symptoms versus onset of dementia symptoms \\ There is evidence from the history that the characteristic symptoms have not been present continuously before the onset of dementia symptoms. \\ Duration and severity \\ Characteristic symptoms have been present, at least intermittently, for $\geq I$ month. Symptoms are severe enough to cause some disruption in the patient's \\ and/or other's functioning. \\ Exclusion of schizophrenia and related psychotic disorders \\ Criteria for schizophrenia, schizoaffective disorder, delusional disorder, or mood disorder with psychotic features have never been met. \\ Relationship to delirium \\ The disturbance does not occur exclusively during course of a delirium. \\ Exclusion of other causes of psychotic symptoms \\ The disturbance is not better accounted for by another general medical condition or direct physiological effects of a substance (eg, a drug of abuse or \\ medication). \\ Associated features (specify) \\ With agitation-when there is evidence from history or examination of prominent agitation with or without physical or verbal aggression. \\ With negative symptoms - when prominent negative symptoms, such as apathy, affective flattening, avolition, or motor retardation, are present. \\ With depression - when prominent depressive symptoms, such as depressed mood, insomnia or hypersomnia, feelings of worthlessness or excessive \\ or inappropriate guilt, or recurrent thoughts of death, are present.
}

treatment (Alexopoulos et al 2004; AGS/AAGP). Despite these findings, only a few studies have prospectively evaluated the antipsychotic effects of this class of compounds in patients with $\mathrm{AD}$ using the criteria defined by Jeste and Finkel (2000). In contrast, most published studies with atypical agents have also included patients with vascular and mixed dementias, and those with behavioral disturbances, such as agitation.

Safety and tolerability of a medication is of great concern while treating the elderly due to their increased sensitivity to adverse events (AEs), the increased likelihood of comorbid health problems (eg, cardiovascular disease), and the potential for some side effects to worsen the progression of dementia (Kindermann et al 2002). Studies have shown that risperidone, olanzapine, and quetiapine can reduce psychotic symptoms and behavioral disturbances in patients with dementia (Katz et al 1999; Defilippi and Crismon 2000; Street et al 2000; Madhusoodanan et al 2001; Tariot et al 2002; Brodaty et al 2003; De Deyn et al 1999, 2004; Zhong et al 2004. However, the side-effect profiles of individual atypical antipsychotics, especially the metabolic effects may adversely influence their overall effectiveness and acceptability (Jeste et al 1999; Masand 2000). Movement disorders, sedation, and orthostasis are associated with an increased risk of falls and subsequent fractures. Anticholinergic side effects may lead to delirium in the elderly and require additional treatment. Analyses of safety data from several studies have raised concerns about an increased risk of cerebrovascular adverse events (CVAEs), such as stroke, with the use of some atypical antipsychotics compared with placebo in elderly patients with dementia (Wooltorton 2002, 2004). This has led FDA to issue warnings on the use of atypical antipsychotics in the treatment of behavioral and psychological symptoms in elderly patients with dementia, particularly those with a history of cerebrovascular disease (US FDA 2003; Health Canada; MHRA). More recently, the FDA issued a separate warning regarding an increased mortality risk in elderly patients with dementia who were treated with atypical antipsychotics (US FDA 2005). We have dealt with these issues in detail in our recent review article (Madhusoodanan et al 2007).

Aripiprazole is a novel atypical antipsychotic that has shown rapid and sustained efficacy and tolerability in shortterm and long-term controlled clinical trials and retrospective studies in patients with schizophrenia, schizoaffective disorder and bipolar disorder (Liebermann 2004; Madhusoodanan et al 2004; Sajatovic et al 2008). Recently FDA approved the use of aripiprazole as an adjunctive to antidepressants for the treatment of major depressive disorder in adults (Prescribing information 2007). Aripiprazole is a partial $\mathrm{D}_{2}$-receptor agonist (Burris et al 2002), 5- $\mathrm{HT}_{2 \mathrm{~A}}$ receptor antagonist (Byars et al 2002), and a partial agonist at 5- $\mathrm{HT}_{1 \mathrm{~A}}$ receptors (Jordan et al 2002). In addition, aripiprazole has been shown to exhibit moderate affinity for the alpha ${ }_{1}$, alpha $_{2}$ and 
histamine $\mathrm{H}_{1}$ receptors and negligible affinity for muscarinic $M_{1}$ receptors (DeLeon et al 2004; Prescribing information 2007).

Three 10-week, placebo-controlled, randomized, doubleblind clinical studies have evaluated the efficacy and tolerability of aripiprazole for the treatment of psychosis related to AD (Table 2a) (Streim et al 2004; De Deyn et al 2005; Mintzer et al 2007). Of these, the studies conducted by De Deyn et al and Streim et al examined flexible dosing of aripiprazole $(2-15 \mathrm{mg} / \mathrm{d})$, and Mintzer et al studied fixed doses of aripiprazole $(2 \mathrm{mg} / \mathrm{d}, 5 \mathrm{mg} / \mathrm{d}, 10 \mathrm{mg} / \mathrm{d})$. Patients in the Streim et al and Mintzer et al studies were either full time nursing home or assisted living facility residents, while patients in the De Deyn et al study were living in assisted living facilities or adult communities, or with a caregiver. The inclusion criteria were delusions/hallucinations lasting for 1 month or longer, Mini Mental State Exam (MMSE; Fostein et al 1975) score of 6-24, and score of more than 6 on delusions or hallucinations items of Neuropsychiatric Inventory (NPI; Cummings et al 1994) scale at baseline.

In the De Deyn et al (2005) study, 208 outpatients (mean age 81.5 years, range 55-95) with AD-associated psychosis and mean MMSE score of 14.35 (aripiprazole) and 14.13 (placebo), were randomized to aripiprazole $(n=106)$ or placebo $(n=102)$. The initial aripiprazole dose of $2 \mathrm{mg} / \mathrm{d}$ was titrated upwards $(5,10$, or $15 \mathrm{mg} / \mathrm{d})$ usually every 2 weeks according to efficacy and tolerability. Overall, 172 patients $(83 \%)$ completed the study. Mean aripiprazole dose at end point was $10.0 \mathrm{mg} / \mathrm{d}$. Patients in this study were noninstitutionalized, in contrast to most studies with other atypicals published to date, which included institutionalized patients (Katz et al 1999; Street et al 2000; Tariot et al 2002; Brodaty et al 2003; De Deyn et al 1999, 2004; Zhong et al 2004). In this study, the degree of cognitive impairment (mean MMSE, 14.35 for aripiprazole, 14.13 for placebo) was less compared with most of the studies with other atypicals (mean MMSE, 6.1-9.3).

In the Streim et al (2004) study, 256 inpatients (mean age 83 years, range 59-96) with AD-associated psychosis and mean MMSE score of 12.9 were randomized to aripiprazole $(n=131)$ or placebo $(n=125)$. The suggested titration for this study was: week 1: $2 \mathrm{mg} / \mathrm{d}$; week 2-3: $5 \mathrm{mg} / \mathrm{d}$; week 4-5: $10 \mathrm{mg} / \mathrm{d}$; week 6-10: $15 \mathrm{mg} / \mathrm{d}$. Mean aripiprazole dose at end point was $8.6 \mathrm{mg} / \mathrm{d}$.

Table 2a Methodology - placebo-controlled studies of aripiprazole in patients with AD-related psychosis (pers comm Jan 8 2008, Bristol-Myers Squibb and Otsuka Pharmaceutical Co, Ltd, Data on file)

\begin{tabular}{|c|c|c|c|}
\hline Reference & Patient population & Study design & Study medication \\
\hline De Dedyn et al 2005 & $\begin{array}{l}208 \text { outpatients } \\
\text { Mean age (in years) 8I.5, } \\
\text { range 55-95 } \\
\text { Mean MMSE score = } 14.35 \\
\text { (aripiprazole). } \\
\text { I4. I3 (placebo) } \\
\text { delusions/ } \\
\text { hallucinations } \geq 1 \text { month } \\
\text { NPI delusions/ } \\
\text { hallucinations score } \geq 6\end{array}$ & $\begin{array}{l}\text { I0 week, randomized double-blind, } \\
\text { multi-center placebo-controlled, } \\
\text { flexible dose study }\end{array}$ & $\begin{array}{l}\text { Aripiprazole } 2-15 \mathrm{mg} / \mathrm{d} \\
(\mathrm{n}=106) \\
\text { Titrated Q } 2 \text { weeks as needed } \\
\text { Mean end point dose }=10 \mathrm{mg} / \mathrm{d} \\
\text { Placebo }(\mathrm{n}=102)\end{array}$ \\
\hline Streim et al 2004 & $\begin{array}{l}256 \text { inpatients } \\
\text { Mean age (in years) 83; } \\
\text { range 59-96 } \\
\text { Mean MMSE score = } 12.9 \\
\text { delusions/ } \\
\text { hallucinations } \geq 1 \text { month } \\
\text { NPI delusions/ } \\
\text { hallucinations score } \geq 6\end{array}$ & $\begin{array}{l}\text { I0 week, randomized double-blind, } \\
\text { multi-center placebo-controlled, } \\
\text { flexible dose study }\end{array}$ & $\begin{array}{l}\text { Aripiprazole } 2-15 \mathrm{mg} / \mathrm{d} \\
(\mathrm{n}=\mid 3 \mathrm{I}) \\
\text { Week I to weeks } 6-10 \text { from } \\
2 \mathrm{mg} / \mathrm{d} \text { to } 15 \mathrm{mg} / \mathrm{d} \\
\text { Mean end point dose }=8.6 \mathrm{mg} / \mathrm{d} \\
\text { Placebo }(\mathrm{n}=125)\end{array}$ \\
\hline Mintzer et al 2007 & $\begin{array}{l}487 \text { inpatients } \\
\text { Mean age, years } 82.2 \text {, } \\
\text { (range) 56.0-96.0 } \\
\text { Mean MMSE score = } 12.4 \\
\text { delusions/hallucinations } \\
\geq \text { I month } \\
\mathrm{NPI} \text { delusions/ } \\
\text { hallucinations score } \geq 6\end{array}$ & $\begin{array}{l}\text { I0 week, randomized double-blind, } \\
\text { multi-center placebo-controlled, } \\
\text { fixed dose study }\end{array}$ & $\begin{array}{l}\text { Aripiprazole } 2 \mathrm{mg} / \mathrm{d}(\mathrm{n}=1 \mathrm{I}) \\
\text { Aripiprazole } 5 \mathrm{mg} / \mathrm{d}(\mathrm{n}=122) \\
\text { Aripiprazole } 5 \mathrm{mg} / \mathrm{d} \times 7 \mathrm{~d} \text {, then } \\
10 \mathrm{mg} / \mathrm{d}(\mathrm{n}=126) \\
\text { Placebo }(\mathrm{n}=12 \mathrm{I}) \\
\text { by week } 6 \text {, patient } \\
\text { with CGI-I } \geq 4 \text { were allowed } \\
\text { open-label treatment with } \\
\text { aripiprazole through week } 10\end{array}$ \\
\hline
\end{tabular}

Abbreviations: CGI-I, Clinical Global Impression of Improvement; MMSE, Mini Mental State Exam; NPI, Neuropsychiatric Inventory. 
In the Mintzer et al (2007) study, 487 inpatients (mean age 82.5 years, range 56-97) with AD-associated psychosis and mean MMSE score of 12.4 were randomized to fixed doses of aripiprazole, $2 \mathrm{mg} / \mathrm{d}(\mathrm{n}=118), 5 \mathrm{mg} / \mathrm{d}(\mathrm{n}=122)$, $10 \mathrm{mg} / \mathrm{d}(\mathrm{n}=126)$ (patients were started on $5 \mathrm{mg} / \mathrm{d}$ for 7 days and the dose was then increased to $10 \mathrm{mg} / \mathrm{d}$ ), or placebo $(\mathrm{n}=121)$. By week 6, patients with Clinical Global Impression of Improvement (CGI-I; Guy 1976) score of $\geq 4$ were allowed open-label treatment with aripiprazole through week 10. In total, 284 patients completed 10 weeks of double-blind therapy.

\section{Results}

\section{Efficacy (Table 2b)}

\section{Primary outcome measures}

In the De Deyn et al (2005) study, the caregiver-assessed NPI Psychosis subscale (Cummings et al 1994) score showed improvements in both groups (aripiprazole -6.55 , placebo $-5.52 ; \mathrm{p}=0.17$ at end point), but the difference between aripiprazole and placebo was not statistically significant.

In the Streim et al (2004) study, there was no statistically significant difference between aripiprazole and placebo on the NPI Psychosis subscale score at week 10. There were decreases in Clinical Global Impression-Severity of Illness (CGI-S; Guy 1976) scores in both aripiprazole and placebo groups, but the difference in the mean change in CGI-S in aripiprazole vs placebo was significant $(\mathrm{p}<0.05)$ only at week 8 .

In the Mintzer et al (2007) study, there was a statistically significant difference between aripiprazole and placebo (aripiprazole $10 \mathrm{mg} / \mathrm{d},-6.87$. placebo, -5.13. p 0.013) on the Neuropsychiatric Inventory-Nursing Home (NPI-NH) Psychosis subscale (Guy 1976; Cummings et al 1994; Wood et al 2000) score at week 10. Mean change in NPI-NH Psychosis subscale score was also significant for the aripiprazole $5 \mathrm{mg}$ group vs placebo at week $8(\mathrm{p}<0.05)$. There was a statistically significant difference $(\mathrm{p}<0.05)$ in the response to treatment as defined by $\geq 50 \%$ reduction in the NPI-NH Psychosis subscale score at week 10 for aripiprazole $(65 \%)$ vs placebo $(50 \%)$.

\section{Secondary outcome measures}

In the De Deyn et al (2005) study, aripiprazole-treated patients showed significantly greater improvements from baseline in physician assessed Brief Psychiatric Rating Scale (BPRS) (Overall and Gorham 1962) Psychosis and BPRS Core subscale scores at end point compared with placebo. There were no statistically significant differences between aripiprazole and placebo in the mean change in BPRS total score (aripiprazole -8.53, placebo -6.58; p value not significant), NPI total (aripiprazole -9.75, placebo -11.20; p value not significant), CGI-S (aripiprazole -0.69 , placebo -0.54 ; $\mathrm{p}$ value not significant ), CGI-I (aripiprazole 3.17, placebo, 3.07; $\mathrm{p}$ value not significant). Patients in both the aripiprazole and placebo groups showed little change in cognitive function over the course of the study, with minimal mean changes $(<1$ point) in MMSE score observed from baseline to end point (aripiprazole -0.81 , placebo -0.53 ; p 0.001). The investigators explained the small improvement in MMSE scores seen in the placebo group as a possible response to the increased attention patients received during the study. The minimal changes observed in both groups and high mean baseline scores, coupled with the wide variation in baseline MMSE scores (from 2 to 23), suggested that these are of little clinical significance. Aripiprazole has negligible affinity for muscarinic $M_{1}$ receptors, and hence has a low potential for cognitive impairment, and has shown improvements in cognitive function in a study in patients with schizophrenia or schizoaffective disorder (Cornblatt et al 2002).

In the Streim et al (2004) study, there was a statistically significant difference $(\mathrm{p}=0.006)$ in the response to treatment as defined by $\geq 50 \%$ reduction in the NPI total score at week 10 for aripiprazole $(46 \%)$ and placebo $(28 \%)$. There were statistically significant improvements in the NPI-NH total scores (aripiprazole -16.4 , placebo -10.0; p 0.009), BPRS total score (aripiprazole, -7.7 placebo, $-5.1 ; \mathrm{p} 0.031$ ) and Cornell Depression in Dementia Scale (CDDS; Alexopoulos et al 1988) total score (aripiprazole -0.13 , placebo -1.98 ; $\mathrm{p} 0.006)$ at week 10 . There were statistically significant $(\mathrm{p}<0.05)$ improvements with aripiprazole vs placebo group in Cohen-Mansfield Agitation Inventory (CMAI; CohenMansfield and Billig 1986; Cohen-Mansfield 1995; Miller et al 1995; Weiner et al 2002) and CGI-I scores.

In the Mintzer et al (2007) study, there was a statistically significant improvement at week 10 with aripiprazole $10 \mathrm{mg} / \mathrm{d}$ vs placebo group in BPRS total score (aripiprazole -7.12 , placebo -4.17 ; p 0.03 ) and in the CGI-S (aripiprazole -0.72 , placebo, $-0.46 ; \mathrm{p} 0.031$ ). There was a significant reduction in the CMAI scores with aripiprazole $5 \mathrm{mg} / \mathrm{d}$ and $10 \mathrm{mg} / \mathrm{d}$ vs placebo at weeks 6 through 10 . There was a significant reduction in the BPRS core score with aripiprazole $5 \mathrm{mg} / \mathrm{d}$ vs placebo at weeks 4,6 , and 8 , and with $10 \mathrm{mg} / \mathrm{d}$ vs placebo at weeks 4 through 10 . There was a significant reduction in the NPI-NH total score with aripiprazole $5 \mathrm{mg} / \mathrm{d}$ vs placebo at weeks 6 and 8 . Aripiprazole $2 \mathrm{mg} /$ day was not efficacious. 


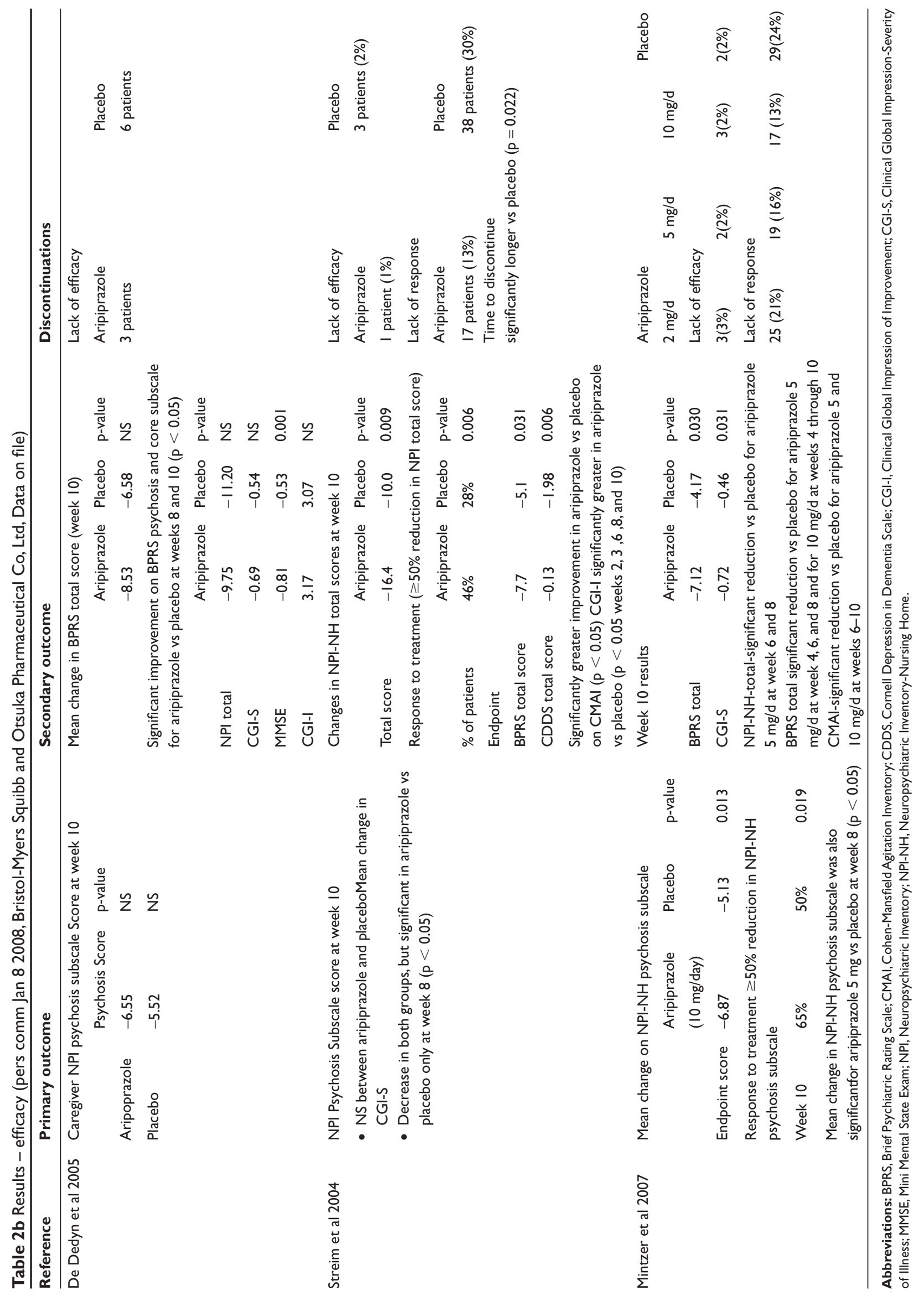


Kostic et al (2005) analyzed the data from the two studies (Streim et al 2004; Mintzer et al 2007) to investigate further the effect of aripiprazole on agitation as measured by reduction in NPI-Agitation Item, CMAI, and Tension/ Hostility/Uncooperativeness/ Excitement scores of BPRS. In the Streim et al (2004) study, NPI agitation/aggression, CMAI, and BPRS Tension/Hostility/Uncooperativeness/ Excitement scores were significantly reduced at study endpoint ( $\mathrm{p}=0.001, \mathrm{p}<0.05, \mathrm{p}<0.05$ respectively). In the Mintzer et al (2007) study, aripiprazole $5 \mathrm{mg} / \mathrm{d}$ and $10 \mathrm{mg} / \mathrm{d}$ demonstrated significant reduction $(\mathrm{p}<0.05)$ of NPI-NH Agitation Item and BPRS Tension/Hostility/Uncooperativeness/Excitement subscore compared with placebo. A significant decrease from baseline on BPRS Tension/ Hostility/Uncooperativeness/Excitement subscore was also observed with aripiprazole $2 \mathrm{mg} / \mathrm{d}$ (beginning at week 6) at study endpoint $(p \leq 0.05)$. The effect of aripiprazole on agitation as measured by BPRS Tension/Hostility/Uncooperativeness/Excitement subscore was seen earlier with higher doses (beginning at week 2 with $10 \mathrm{mg} / \mathrm{d}$ and beginning at week 4 with $5 \mathrm{mg} / \mathrm{d}$ ) compared with $2 \mathrm{mg} / \mathrm{d}$.

Discontinuation due to lack of efficacy occurred in 3 patients on aripiprazole and 6 patients on placebo in the De Deyn et al (2005) study, and in 1 patient on aripiprazole and 3 patients on placebo in the Streim et al study (2004). Discontinuation due to lack of response occurred in $13 \%$ of patients on aripiprazole vs $30 \%$ of patients on placebo, and time to discontinuation was significantly longer in the aripiprazole group vs the placebo group $(\mathrm{p}=0.022)$ in the Streim et al (2004) study. In the Mintzer et al (2007) study, discontinuation due to lack of efficacy occurred in $3 \%$ of patients on $2 \mathrm{mg} / \mathrm{d}$ of aripiprazole, $2 \%$ of patients on $5 \mathrm{mg} / \mathrm{d}$ of aripiprazole, $2 \%$ of patients on $10 \mathrm{mg} / \mathrm{d}$ of aripiprazole, and $2 \%$ of patients on placebo. Discontinuation due to lack of response occurred in $21 \%$ of patients on $2 \mathrm{mg} / \mathrm{d}$ of aripiprazole, $16 \%$ of patients on $5 \mathrm{mg} / \mathrm{d}$ of aripiprazole, $13 \%$ of patients on $10 \mathrm{mg} / \mathrm{d}$ of aripiprazole, and $24 \%$ of patients on placebo. Thus the discontinuation due to lack of response was highest in the lowest-dose group and placebo group.

\section{Tolerability (Table 2c)}

In the De Deyn et al (2005) study, AEs were generally mild to moderate and included (aripiprazole vs placebo): urinary tract infection ( $8 \%$ vs $12 \%$ ), accidental injury ( $8 \%$ vs $5 \%$ ), somnolence ( $8 \%$ vs $1 \%$ ), and bronchitis ( $6 \%$ vs $3 \%$ ). Somnolence was mild and not associated with falls or accidental injury. There were no significant differences vs placebo in the extrapyramidal symptoms (EPS) scores, or clinically significant electrocardiogram (ECG) abnormalities, vital signs, or weight.

In the Streim et al (2004) study, AEs that occurred at the rate of $\geq 10 \%$ in the aripiprazole group were accidental injury, somnolence, urinary tract infection, ecchymosis, asthenia, vomiting, and rash, and in the placebo group were accidental injury, urinary act infection, ecchymosis, and rash. EPS occurred in 5\% of aripiprazole group vs $4 \%$ of placebo group, somnolence occurred in 14\% of aripiprazole group vs $4 \%$ of placebo group, and accidental injuries occurred in $21 \%$ of aripiprazole group vs $30 \%$ of placebo group.

In the Mintzer et al (2007) study, AEs occurring at $\geq 10 \%$ incidence in any dosage group of aripiprazole were accidental injury, agitation, peripheral edema, extremity pain, somnolence, urinary incontinence, asthenia, vomiting, and skin ulcer, and in the placebo group, accidental injury, anorexia, ecchymosis, and agitation. EPS occurred in $8 \%$ of aripiprazole $2 \mathrm{mg} / \mathrm{d}$ group, $7 \%$ in aripiprazole $5 \mathrm{mg} / \mathrm{d}$ group, $7 \%$ in aripiprazole $10 \mathrm{mg} / \mathrm{d}$ group, and $6 \%$ in the placebo group. Somnolence occurred in 3\% of aripiprazole $2 \mathrm{mg} / \mathrm{d}$ group, $10 \%$ in aripiprazole $5 \mathrm{mg} / \mathrm{d}$ group, $7 \%$ in aripiprazole $10 \mathrm{mg} / \mathrm{d}$ group, and 3\% in the placebo group. Accidental injuries occurred in $30 \%$ of aripiprazole $2 \mathrm{mg} / \mathrm{d}$ group, $24 \%$ in aripiprazole $5 \mathrm{mg} / \mathrm{d}$ group, $20 \%$ in aripiprazole $10 \mathrm{mg} / \mathrm{d}$ group, and $19 \%$ in the placebo group.

Analysis of the data on mortality in elderly patients with dementia-related psychosis (Breder et al 2005; pers comm Jan 8 2008, Bristol-Myers Squibb and Otsuka Pharmaceutical Co, Ltd, Data on file) of the three trials (Streim et al 2004; De Deyn et al 2005; Minzter et al 2007) for deaths that occurred during or within 30 days of discontinuation from the placebocontrolled phase of the clinical trial showed that incidence of deaths was 3.5\% in aripiprazole-treated patients and $1.7 \%$ in placebo-treated patients $(\mathrm{p}=0.139)$. None of the deaths were considered to be treatment-related. Deaths were mostly associated with cardiovascular or infectious conditions.

In these three trials (Streim et al 2004; De Deyn et al 2005; Minzter et al 2007), there was increased incidence of CVAEs (eg, stroke, transient ischemic attack), including fatalities, in aripiprazole-treated patients. In the fixed-dose study of Mintzer et al (2007) there was a statistically significant dose-response relationship for CVAEs in patients treated with aripiprazole.

In an analysis (pers comm Jan 8 2008, Bristol-Myers Squibb and Otsuka Pharmaceutical Co, Ltd, Data on file) of the three 10-week, placebo-controlled studies of aripiprazole in elderly patients with psychosis associated with $\operatorname{AD}(n=938$, mean age 82.4 years, range 56-99 years), the 


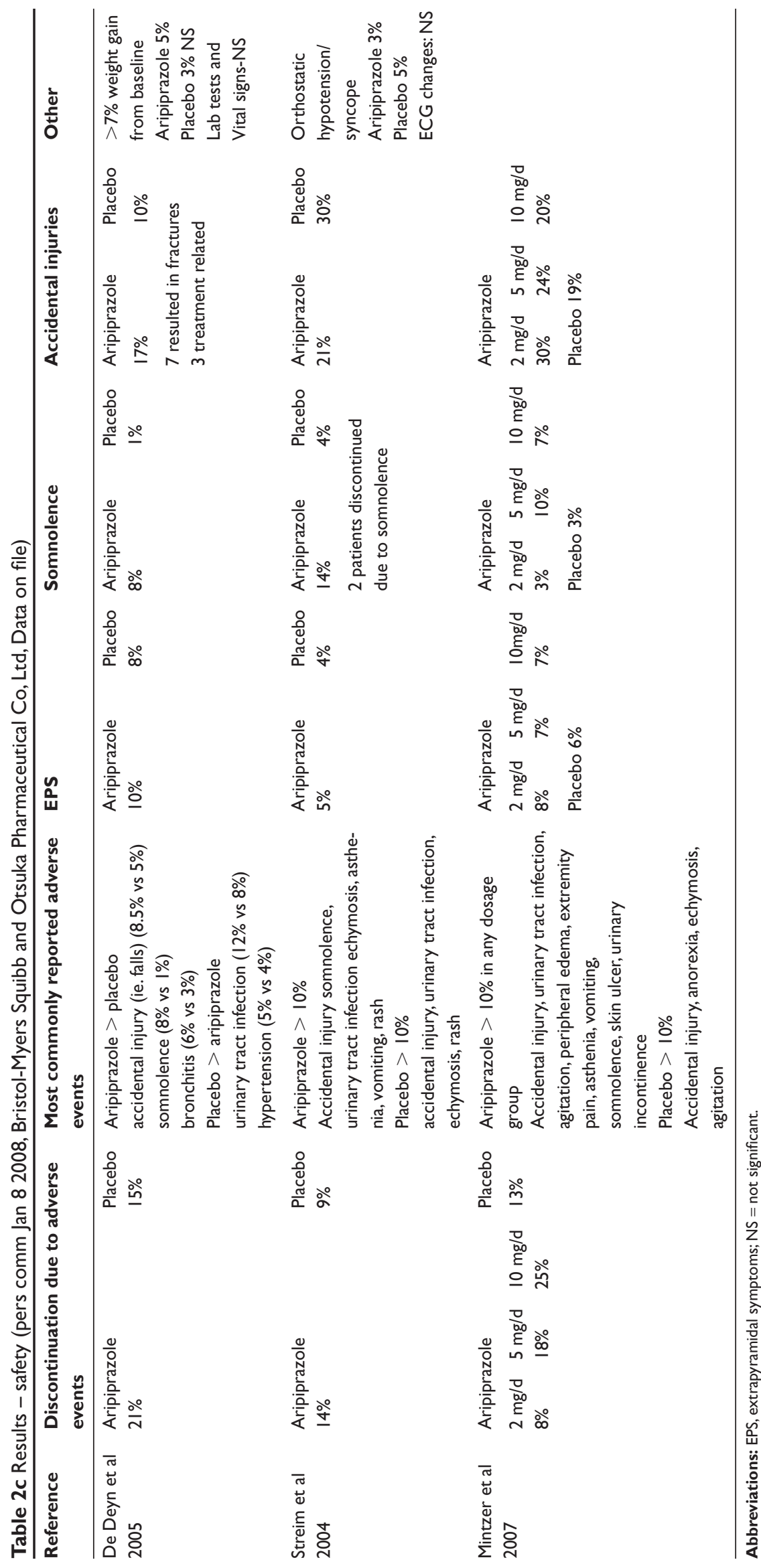


treatment-emergent AEs that were reported at an incidence of $\geq 3 \%$ and at least twice that for placebo were lethargy (placebo 2\%, aripiprazole 5\%), somnolence (including sedation) (placebo 3\%, aripiprazole $8 \%$ ), and incontinence (primarily, urinary incontinence) (placebo 1\%, aripiprazole $5 \%$ ), excessive salivation (placebo $0 \%$, aripiprazole $4 \%$ ), and lightheadedness (placebo 1\%, aripiprazole 4\%).

Discontinuation due to AEs occurred in 10 patients on aripiprazole vs 7 patients on placebo in the De Deyn et al (2005) study, $14 \%$ on aripiprazole vs $9 \%$ patients on placebo in the Streim et al (2004) study. In the Mintzer et al (2007) study, discontinuation occurred in $8 \%$ on aripiprazole $2 \mathrm{mg} / \mathrm{d}$, $18 \%$ on aripiprazole $5 \mathrm{mg} / \mathrm{d}, 25 \%$ on aripiprazole $10 \mathrm{mg} / \mathrm{d}$ vs $13 \%$ patients on placebo. Thus the discontinuation due to AEs increased with increasing dose. The most common AE leading to discontinuation among the aripiprazole and placebo groups were asthenia and agitation, respectively. Discontinuations due to asthenia appeared to be dose-related, with the greatest number of patients experiencing asthenia in the aripiprazole $10 \mathrm{mg}$ /day dose group (placebo $1 \%$, aripiprazole $2 \mathrm{mg} /$ day $1 \%$, aripiprazole $5 \mathrm{mg} /$ day $2 \%$, and aripiprazole $10 \mathrm{mg} /$ day $4 \%$ ).

\section{Discussion}

The Clinical Antipsychotic Trials of Intervention Effectiveness-Alzheimer's Disease (CATIE-AD) study (Schneider et al 2006) evaluated the overall effectiveness of three of the most widely used antipsychotic medications compared with placebo among patients in non-nursing home settings, who were experiencing delusions, hallucinations, aggression, or agitation. The study followed the participants over 9 months and also included the involvement of caregivers. In this 42-site, double-blind, placebo-controlled trial, 421 outpatients suffering from AD and having psychosis, aggression, or agitation were randomly assigned to receive olanzapine (mean dose, $5.5 \mathrm{mg} / \mathrm{d}$ ), quetiapine (mean dose, $56.5 \mathrm{mg} / \mathrm{d}$ ), risperidone (mean dose, $1.0 \mathrm{mg} / \mathrm{d}$ ), or placebo. There were no significant differences among treatments for the main outcome measures, ie, time to discontinuation of treatment for any reason and number of patients with at least minimal improvement on the Clinical Global Impression of Change (CGIC) (Schneider et al 1997) scale at 12 weeks. The median time to discontinuation of treatment due to a lack of efficacy favored olanzapine and risperidone over quetiapine and placebo. The time to discontinuation of treatment due to adverse events or intolerability favored placebo. This study showed that the adverse effects of atypical antipsychotics offset their ben- efits in the treatment of psychosis, aggression, or agitation in patients with $\mathrm{AD}$.

The flexible dose studies of aripiprazole showed modest effect (Streim et al 2004; De Deyn et al 2005). In these two studies, which assessed the efficacy of flexible doses of aripiprazole up to $15 \mathrm{mg} / \mathrm{d}$ in patients with $\mathrm{AD}$, the change from baseline NPI-NH Psychosis Subscale score was similar for the aripiprazole and placebo groups, with significant improvements compared with placebo in secondary measures of psychosis (eg, BPRS score subscale and psychosis subscale) (De Deyn et al 2005) and other behavioral symptoms (eg, CMAI, CDDS,CGI-I, NPI$\mathrm{NH}$ scores) (Streim et al 2004) in patients suffering from psychosis associated with AD. The study assessing the efficacy of fixed doses of aripiprazole (Mintzer et al 2007) showed that aripiprazole $10 \mathrm{mg} / \mathrm{d}$ was efficacious and safe for psychosis associated with AD, significantly improving psychotic symptoms and agitation, and showed improvement in both primary and secondary outcome measures in that patient population.

The safety and tolerability profile of antipsychotic treatment is of particular concern in elderly patients who are more susceptible to adverse effects such as EPS, delirium due to anticholinergic adverse events, and orthostatic hypotension. There is also a high prevalence of co-existing metabolic (eg, high cholesterol, diabetes mellitus) and cardiovascular illnesses (eg, hypertension, ischemic heart disease) in the elderly. In addition, AEs may be associated with falls and accidents resulting in fractures in the elderly. Hence the risk of such AEs should be considered while choosing a medication and making treatment decisions. It is therefore important to note that the incidence of EPSrelated AEs in these studies was low across all treatment groups. This concurs with the safety profile of aripiprazole in patients with schizophrenia and bipolar disorder in adults and in elderly patients (Marder et al 2003; Madhusoodanan et al 2004; Sajatovic et al 2008). However, not all studies with atypical antipsychotics in patients with AD have shown EPS-related adverse events similar to placebo (Street et al 2000). High levels of somnolence may also be associated with falls in the elderly. In the two studies assessing the flexible doses of aripiprazole, occurrence of somnolence showed a $>5 \%$ difference between the aripiprazole and placebo groups. In the study assessing fixed doses of aripiprazole, the incidence of somnolence with aripiprazole was low (7\% at the $10 \mathrm{mg} / \mathrm{d}$ dose) and did not increase with dose. Higher somnolence rates have been observed in previous studies with other atypical antipsychotics. for 
example, 36.5\% with risperidone (Brodaty et al 2003) and $35.8 \%$ with olanzapine (Street et al 2000). There was no significant difference between placebo and aripiprazole in all the three studies for weight change, in contrast to studies with other atypical antipsychotics where significantly higher weight gain was observed with both olanzapine (De Deyn et al 2004) and risperidone (Brodaty et al 2003) vs placebo in patients with AD.

Recently, CVAEs have emerged as a significant issue with the use of atypical antipsychotics in elderly individuals (Wooltorton 2002, 2004). This led the FDA to issue a warning. However, some retrospective cohort studies have suggested that conventional and atypical antipsychotics do not differ significantly in their risk of CVAEs (Herrmann et al 2004; Finkel et al 2005) or mortality (Wang et al 2005) in older adults. CVAEs were reported for 7 aripiprazole-treated patients during the Mintzer et al (2007) fixed dose study ( 1 in the $2 \mathrm{mg} / \mathrm{d}$ dose group, 2 in the $5 \mathrm{mg} / \mathrm{d}$ dose group, and 4 in the $10 \mathrm{mg} / \mathrm{d}$ dose group), compared with no patients in the placebo group. The effect was statistically dose-dependent ( $\mathrm{p}=0.03$, Cochran-Mantel-Haenszel [CMH] row means score test). All CVAEs reported with aripiprazole occurred in subjects with a prior history of CVA, stroke, or related risk factors. It is also important to note that the FDA has issued a black box warning for increased mortality risk in elderly patients with dementia, treated with atypical antipsychotics (US FDA 2003). Analyses of 17 placebo-controlled trials (modal duration of 10 weeks) in these patients revealed a risk of death in the drug-treated patients of 1.6 to 1.7 times to that seen in placebo-treated patients. Over the course of a typical 10 -week controlled trial, the rate of death in drug-treated patients was about $4.5 \%$, compared with a rate of about $2.6 \%$ in the placebo group. Although the causes of death were varied, most of the deaths appeared to be the result of either cardiovascular causes (eg, heart failure, sudden death) or infections (eg, pneumonia). Aripiprazole should be used with caution in patients with known cardiovascular disease, cerebrovascular disease, or conditions that would predispose patients to hypotension. The risks and benefits of arpipirazole in the treatment of psychosis of AD should be considered by the clinicians and discussed with the patients/caregivers (Schneider et al 2005).

A thorough evaluation of the medical and psychiatric status along with a comprehensive treatment approach including environmental manipulation are required prior to considering use of atypical antipsychotic in patients with psychosis associated with AD. The efficacy results in the study by Mintzer et al (2007) show that aripiprazole
$10 \mathrm{mg} / \mathrm{d}$ is an effective dose for these patients, although some patients achieved significant benefit with aripiprazole $5 \mathrm{mg} / \mathrm{d}$. The dose-effectiveness relationship is further supported by the rate of discontinuation due to lack of efficacy, which was greatest in the $2 \mathrm{mg} / \mathrm{d}$ dose group. However, when selecting an appropriate dose, the discontinuation rate due to dose-related adverse events should also be considered. The rates of discontinuation due to adverse events for the 5 and $10 \mathrm{mg} / \mathrm{d}$ doses (18\% and $25 \%$, respectively) were higher than those reported in the flexible-dose aripiprazole studies in noninstitutionalized patients (9.4\%) (De Deyn et al 2005) and in institutionalized patients (14\%) (Streim et al 2004). In both of the flexible-dose studies, patients were started with $2 \mathrm{mg} / \mathrm{d}$ and titrated gradually to higher aripiprazole doses. This suggests that slow titration from a low initial dose may improve the tolerability and prove to be the most clinically appropriate strategy for starting aripiprazole treatment in this elderly patient population.

\section{Conclusion}

The control of psychotic symptoms is important for improving outcome in elderly patients with AD. Furthermore, treatment of the psychotic symptoms improves patient quality of life, decreases caregiver burden, decreases the need for institutionalization, and reduces overall healthcare costs. There are no psychotropic medications approved by the FDA for the treatment of psychosis of AD. The limited evidence available for atypical antipsychotics suggests that they offer modest benefits over placebo for treating psychosis. The studies evaluating aripiprazole suggest that it may also be beneficial in treatment of psychosis for patients with AD. However, the benefits of relieving psychosis need to be balanced against the risk of neurologic, metabolic, and cardiovascular AEs in each individual patient. The safety and tolerability profile seen with aripiprazole suggests a low potential for negative impact on overall patient health and makes aripiprazole a reasonable treatment option. However, in the absence of head-to-head comparison studies between aripiprazole and other atypical antipsychotics, it is difficult to conclude whether there is any added value of the uses of aripiprazole. Further studies comparing the efficacy and tolerability of aripiprazole versus other atypical antipsychotics in psychosis of AD are needed to guide treatment choice among the atypical antipsychotics agents.

\section{Disclosures}

SM is a consultant to and on the Speakers' Bureau for BristolMyers Squibb. PS has nothing to disclose. 


\section{References}

AGS/AAGP: Consensus Statement on Improving the Quality of Mental Health Care in US Nursing Homes: Management of Depression and Behavioral Symptoms Associated with Dementia [online]. Accessed Dec 2005.URL: http://www.psychiatrist.com.ezproxy.med.nyu.edu/ privatepdf/2004/v65s02/v65s0203.pdf.

Alexopoulos GS, Abrams RC, Young RC, et al. 1988. Cornell Scale for Depression in Dementia. Biol Psychiatry, 23:271-84.

Alexopoulos GS, Streim J, Carpenter D, et al. 2004. The Expert Consensus Guideline Series: using antipsychotics in older patients. $J$ Clin Psychiatry, 65(Suppl 2):1-105.

Bassiony MM, Steinberg MS, Warren A, et al. 2000. Delusions and hallucinations in Alzheimer's disease: prevalence and clinical correlates. Int J Geriatr Psychiatry, 15:99-107.

Breder C, Kostic D, Forbes A, et al. 2005. Overall safety of aripiprazole in trials of patients with psychosis of Alzheimer's dementia (poster). Presented at the 158th American Psychiatric Association Meeting. 2005 May 21-26. Atlanta, Georgia.

Brodaty H, Ames D, Snowdon J, et al. 2003. A randomized placebocontrolled trial of risperidone for the treatment of aggression, agitation, and psychosis of dementia. J Clin Psychiatry, 64:134-43.

Burris KD, Molski TF, Xu C, et al. 2002. Aripiprazole, a novel antipsychotic, is a high-affinity partial agonist at human dopamine D2 receptors. $J$ Pharmacol Exp Ther, 302:381-9.

Byars A, Burris KD, Jordan S, et al. 2002. Aripiprazole, a dopamineserotonin system stabilizer. Eur Neuropsychopharmacol, 12:S290.

Chui HC, Lyness SA, Sobel E, et al. 1994. Extrapyramidal signs and psychiatric symptoms predict faster cognitive decline in Alzheimer's disease. Arch Neurol, 51:676-81.

Cohen-Mansfield J. 1995. Assessment of disruptive behavior/agitation in the elderly: function, methods, and difficulties. $J$ Geriatr Psychiatry Neurol, 8:52-60.

Cohen-Mansfield J, Billig N. 1986. Agitated behaviors in the elderly. A conceptual review. J Am Geriatr Soc, 34:711-21.

Cornblatt B, Kern RS, Carson WH, et al. 2002. Neurocognitive effects of aripiprazole versus olanzapine in stable psychosis. Int J Neuropsychopharmacol, 5(suppl 1): S185.

Cummings JL, Mega M, Gray K, et al. 1994. The Neuropsychiatric Inventory: comprehensive assessment of psychopathology in dementia. Neurology, 44:2308-14

De Deyn PP, Carrasco MM, Deberdt W, et al. 2004. Olanzapine versus placebo in the treatment of psychosis with or without associated behavioral disturbances in patients with Alzheimer's disease. Int $J$ Geriatr Psychiatry, 19:115-26.

De Deyn PP, Rabheru K, Rasmussen A, et al. 1999. A randomized trial of risperidone, placebo, and haloperidol for behavioral symptoms of dementia. Neurology, 53:946-55.

De Deyn P, Jeste DV, Swanink R, et al. 2005. Aripiprazole for the treatment of psychosis in patients with Alzheimer's disease: a randomized, placebocontrolled study. J Clin Psychopharmacol, 25:463-7.

Defilippi JL, Crismon ML. 2000. Antipsychotic agents in patients with dementia. Pharmacotherapy, 20:23-33.

DeLeon A, Patel NC, Crismon ML. 2004. Aripiprazole: a comprehensive review of its pharmacology, clinical efficacy, and tolerability. Clin Ther, 26:649-66.

Devanand DP, Brockington CD, Moody BJ, et al. 1992. Behavioral syndromes in Alzheimer's disease. Int Psychogeriatr, 4(Suppl 2):161-84.

Doody RS, Stevens JC, Beck C, et al. 2001. Practice parameter: management of dementia (an evidence-based review). Report of the Quality Standards Subcommittee of the American Academy of Neurology. Neurology, 56:1154-66.

Eustace A, Coen R, Walsh C, et al. A 2002. longitudinal evaluation of behavioural and psychological symptoms of probable Alzheimer's disease. Int J Geriatr Psychiatry, 17:968-73.

Everitt DE, Fields DR, Soumerai SS, et al. 1991. Resident behavior and staff distress in the nursing home. J Am Geriatr Soc, 39:792-8.
Finkel S, Kozma C, Long S, et al. 2005. Risperidone treatment in elderly patients with dementia: relative risk of cerebrovascular events versus other antipsychotics. Int Psychogeriatr, 17:617-29.

Folstein MF, Folstein SE, McHugh PR. 1975. "Mini-mental state". A practical method for grading the cognitive state of patients for the clinician. J Psychiatr Res, 12:189-98.

Guy W. 1976. Clinical Global Impressions (CGI). In: ECDEU Assessment Manual for Psychopharmacology. US Department of Health, Education, and Welfare Publication (ADM) 76-338. Rockville, MD: National Institute of Mental Health. p 218-22.

Health Canada. 2005. Health Canada advises consumers about important safety information on atypical antipsychotic drugs and dementia. Health Canada.

Herrmann N, Mamdani M, Lanctot KL. 2004. Atypical antipsychotics and risk of cerebrovascular accidents. Am J Psychiatry, 161:1113-15.

Hopkins MW, Libon DJ. 2005. Neuropsychological functioning of dementia patients with psychosis. Arch Clin Neuropsychol, 20:771-83.

Jeste DV, Rockwell E, Harris MJ, et al. 1999. Conventional versus newer antipsychotics in elderly patients. Am J Geriatr Psychiatry, 7:70-6.

Jeste DV, Finkel SI. 2000. Psychosis of Alzheimer's disease and related dementias: diagnostic criteria for a distinct syndrome. Am J Geriatr Psychiatry, 8:29-34.

Jordan S, Koprivica V, Chen R, et al. 2002. The antipsychotic aripiprazole is a potent, partial agonist at the human $5-\mathrm{HT}(1 \mathrm{~A})$ receptor. Eur J Pharmacol, 441:137-40.

Katz IR, Jeste DV, Mintzer JE, et al. 1999. Comparison of risperidone and placebo for psychosis and behavioral disturbances associated with dementia: a randomized, double-blind trial. Risperidone Study Group. J Clin Psychiatry, 60:107-15

Kindermann SS, Dolder CR, Bailey A, et al. 2002. Pharmacological treatment of psychosis and agitation in elderly patients with dementia: four decades of experience. Drugs Aging, 19:257-76.

Kostic D, Breder C, Marcus R, et al. 2005. Aripiprazole for treatment of agitation in inpatients with psychosis of Alzheimer's dementia (poster). Presented at the 158th American Psychiatric Association Meeting. May 21-26 2005. Atlanta, Georgia.

Lieberman JA. 2004. Partial dopamine agonists: a new class of antipsychotic. CNS Drugs, 18:251-67.

Lopez OL, Wisniewski SR, Becker JT, et al. 1999. Psychiatric medication and abnormal behavior as predictors of progression in probable Alzheimer disease. Arch Neurol, 56:1266-72.

Madhusoodanan S, Shah P, Brenner R, Gupta S. 2007. Pharmacological treatment of the psychosis of Alzheimer's disease. What is the best approach? CNS Drugs, 21:101-15.

Madhusoodanan S, Brenner R, Gupta S, et al. 2004. Clinical experience with aripiprazole treatment in ten elderly patients with schizophrenia or schizoaffective disorder: retrospective case studies. CNS Spectrums, 9: 862-7.

Madhusoodanan S, Sinha S, Brenner R, et al. 2001. Use of olanzapine for elderly patients with psychotic disorders: a review. Ann Clin Psychiatry, 13:201-13.

Marder SR, McQuade RD, Stock E, et al. 2003. Aripiprazole in the treatment of schizophrenia: safety and tolerability in short-term, placebocontrolled trials. Schizophr Res, 61:123-36.

Masand PS. 2000. Side effects of antipsychotics in the elderly. $J$ Clin Psychiatry, 61(Suppl 8): 43-49.

MHRA: Summary of clinical trial data on cerebrovascular adverse events (CVAEs) in randomised clinical trials of risperidone conducted in patients with dementia [online]. Accessed December 2005. URL: http://www.mhra.gov.uk/home/groups/pl-p/documents/drugsafetymessage/con019490.pdf.

Miller RJ, Snowdon J, Vaughan R. 1995. The use of the Cohen-Mansfield Agitation Inventory in the assessment of behavioral disorders in nursing homes. J Am Geriatr Soc, 43:546-9.

Mintzer JE, Tune LE, Breder CD, et al. 2007. Aripiprazole for the treatment of psychoses in institutionalized patients with Alzheimer dementia: a multicenter, randomized, double-blind, placebo-controlled assessment of three fixed doses. Am J Geriatr Psychiatry, 15:918-31. 
Overall JE, Gorham DR. 1962. The Brief Psychiatric Rating Scale. Psychol Rep, 10:799-812.

Paulsen JS, Salmon DP, Thal LJ, et al. 2000. Incidence of and risk factors for hallucinations and delusions in patients with probable $\mathrm{AD}$. Neurology, 54:1965-71.

Prescribing information on aripiprazole. 2007. Bristol Myers Squibb Company and Otsuka Pharmaceutical Co, Ltd. revised Nov 2007.

Ropacki SA, Jeste DV. 2005. Epidemiology of and risk factors for psychosis of Alzheimer's dementia: a review of 55 studies published form 1990 to 2003. Am J Psychiatry, 162:2022-30.

Sajatovic M, Coconcea N, Ignacio R, et al. 2008. Aripiprazole therapy in 20 older adults with bipolar disorder: A 12-week, open label trial. J Clin Psychiatry, 69:1:41-6.

Schneider L, Tariot P, Dagerman K, et al. 2006. Effectiveness of atypical antipsychotic drugs in patients with Alzheimer's disease. $N$ Engl $J$ Med, 355:1525-38.

Schneider LS, Olin JT, Doody RS, et al. 1997. Validity and reliability of the Alzheimer's Disease Cooperative Study-Clinical Global Impression of Change: the Alzheimer's Disease Cooperative Study. Alzheimer Dis Assoc Disord, 11(Suppl 2):S22-S32.

Schneider LS, Dagerman KS, Insel P. 2005. Risk of death with atypical antipsychotic drug treatment for dementia. Meta-analysis of randomized placebo-controlled trials. JAMA, 294:1934-43.

Street JS, Clark WS, Gannon KS, et al. 2000. Olanzapine treatment of psychotic and behavioral symptoms in patients with Alzheimer disease in nursing care facilities: a double-blind, randomized, placebo-controlled trial. The HGEU Study Group. Arch Gen Psychiatry, 57:968-76.

Streim JE, Breder C, Swanink R, et al. 2004. Flexible dose aripiprazole in psychosis of Alzheimer's dementia [poster]. Presented at the 157th American Psychiatric Association Meeting. May 1-6 2004. New York, NY.
Tariot PN, Schneider L, Katz I, et al. 2002. Quetiapine in nursing home residents with Alzheimer's dementia and psychosis. Presented at the 15th annual meeting of the American Association for Geriatric Psychiatry. Feb 24-27, 2002. Orlando, Fl.

US Food and Drug Administration. 2003. 2003 safety alert: risperidone (Risperdal) [Dear Healthcare Professional Letter]. Rockville, MD: US Food and Drug Administration, April 16, 2003.

US Food and Drug Administration. 2005. FDA Public Health Advisory. Deaths with antipsychotics in elderly patients with behavioral disturbances. Rockville, MD: US FDA.

Wang PS, Schneeweiss S, Avorn J, et al. 2005. Risk of death in elderly users of conventional vs. atypical antipsychotic medications. $N$ Engl J Med, 353:2335-41.

Weiner MF, Tractenberg RE, Jin S, et al. 2002. Assessing Alzheimer's disease patients with the Cohen-Mansfield Agitation Inventory: scoring and clinical implications. J Psychiatr Res, 36:19-25.

Wood S, Cummings JL, Hsu MA, et al. 2000. The use of the neuropsychiatric inventory in nursing home residents. Characterization and measurement. Am J Geriatr Psychiatry, 8:75-83.

Wooltorton E. 2002. Risperidone (Risperdal): increased rate of cerebrovascular events in dementia trials. CMAJ, 167:1269-70.

Wooltorton E. 2004. Olanzapine (Zyprexa): increased incidence of cerebrovascular events in dementia trials. CMAJ, 170:1395.

Zhong K, Tariot P, Minkwitz M, et al. 2004. Quetipine for treatment of agitation in elderly institutionalized patients with dementia: a randomized double blind trial. American College of Neuropsychopharmacology annual meeting, Dec 2004. San Juan, Puerto Rico. 
